\title{
Genetic Diversity and Host Range of Verticillium dahliae Isolates from Artichoke and Other Vegetable Crops in Spain
}

\author{
M. Berbegal, Instituto Agroforestal Mediterráneo, Universidad Politécnica de Valencia, Camino de Vera s/n, 46022 \\ Valencia, Spain; A. Ortega, Departamento de Producción Vegetal y Microbiología, Escuela Politécnica Superior de \\ Orihuela, Universidad Miguel Hernández, Ctra. Beniel km 3.2, 03312 Orihuela, Alicante, Spain; M. M. Jiménez- \\ Gasco, Department of Plant Pathology, The Pennsylvania State University, University Park 16802; C. Olivares- \\ García and R. M. Jiménez-Díaz, Departamento de Agronomía, ETSIAM, Universidad de Córdoba, and Instituto de \\ Agricultura Sostenible, CSIC, Campus Rabanales, Edificio C-4 'Celestino Mutis', 14071 Córdoba, Spain; and \\ J. Armengol, Instituto Agroforestal Mediterráneo, Universidad Politécnica de Valencia
}

\begin{abstract}
Berbegal, M., Ortega, A., Jiménez-Gasco, M. M., Olivares-García, C., Jiménez-Díaz, R. M., and Armengol, J. 2010. Genetic diversity and host range of Verticillium dahliae isolates from artichoke and other vegetable crops in Spain. Plant Dis. 94:396-404.

Artichoke is severely affected by Verticillium wilt, caused by Verticillium dahliae, in easterncentral Spain, which is one of the most important vegetable-cropping areas in the country. To determine genetic and virulence variability in local populations of $V$. dahliae, 18 isolates collected from artichoke and other vegetable species cultivated in eastern-central Spain were selected to represent local vegetative compatibility groups (VCGs). Diversity in the isolates was characterized by molecular markers and virulence in 12 important hosts for that region. Recently developed microsatellite markers (simple-sequence repeats) and polymorphic sequences were used to assess the genetic variation among those isolates to reveal any association occurring among host source, VCG, and virulence. Although all isolates caused severe disease symptoms on artichoke, cardoon, eggplant, and watermelon, those from artichoke had a limited host range and isolates from watermelon, muskmelon, and eggplant were not pathogenic to some of the hosts tested. VCG diversity was related to differential virulence in certain hosts.
\end{abstract}

Verticillium wilts are economically important diseases of dicotyledonous crops worldwide and are caused by the soilborne pathogen Verticillium dahliae Kleb. (35). Verticillium wilt negatively affects artichoke production (Cynara cardunculus L. var. scolymus (L.) Fiori) in the Comunidad Valenciana region located in easterncentral Spain, one of the most important vegetable-cropping areas in the country $(1,4)$. Knowledge about the genetic and virulence diversity in local populations of $V$. dahliae associated with different crops is a key component for the management of Verticillium wilt diseases, particularly through the use of host resistance and choice of crop rotation in a given region $(12,36,44,46)$. Studies during the last decade have shown that genetic diversity in $V$. dahliae populations is higher than previously expected (39). Also, severe disease outbreaks may emerge in a region on vegetable species previously considered to be nonhosts of $V$. dahliae $(2,6,7,10,24,36,39)$.

Corresponding author: M. Berbegal

E-mail: mobermar@etsia.upv.es

Accepted for publication 30 October 2009.

doi:10.1094/PDIS-94-4-0396

(c) 2010 The American Phytopathological Society
Studies also have demonstrated that $V$. dahliae from certain hosts shows a degree of host specificity and differential virulence $(7,19,38)$. For instance, $V$. dahliae isolates from cocoa and pepper have limited host ranges $(7,38,45)$, and cotton isolates differing in virulence (defined as the amount of disease caused in a host genotype) to cotton cultivars show differential virulence on other herbaceous crops $(28,41)$.

Genetic diversity within $V$. dahliae populations has been studied mainly by means of vegetative compatibility grouping and molecular analyses $(10,20,26)$. Isolates that are vegetatively compatible belong to the same vegetative compatibility group (VCG) based on their genetically controlled ability to undergo hyphal anastomosis and form stable heterokaryons $(23,29)$. For strictly asexually reproducing fungi, hyphal fusion is necessary for genetic exchange among different isolates (35). Therefore, $V$. dahliae isolates from different VCGs are thought to be genetically isolated populations which may vary in some ecological, physiological, and virulence traits $(12,23,39)$. A correlation between virulence and the VCG of V. dahliae isolates has been demonstrated in certain hosts $(5,16,22,26,46,48)$. Conversely, $V$. dahliae isolates in the same VCG but from different hosts may differ in host range, suggesting that a pathogenicity trait might be determined by selection pressure established by cropping practices $(7,12$, 45,48).

Studies on the relationships between VCGs, virulence, and molecular diversity within $V$. dahliae often yielded contradictory results. Bhat and Subbarao (6) reported that host specificity and virulence diversity were not associated to random amplified polymorphic DNA (RAPD) patterns. In contrast, RAPD markers clearly differentiated between $V$. dahliae isolates from woody and herbaceous hosts (33). Similarly, RAPD markers demonstrated correlation between molecular grouping, VCGs, and virulence among isolates from different hosts $(47,48)$.

The diversity in VCG and VCGassociated virulence among artichoke $V$. dahliae isolates from the main artichokegrowing areas in the Comunidad Valenciana region was recently investigated (20). Four VCGs (VCG1A, VCG2A, VCG2B and VCG4B) were identified associated with affected artichokes. VCG2B was the predominant group. Using a large sample of isolates representative of each VCG, it was concluded that VCG2B and VCG4B isolates were the most virulent to artichoke whereas isolates in VCG1A and a single heterokaryon self-incompatible (HSI) isolate were the least virulent to that host. Furthermore, specific polymerase chain reaction (PCR) markers and amplified fragment length polymorphism (AFLP) analysis demonstrated that a correlation existed between molecular differences among artichoke isolates in VCG2B and virulence to artichoke $(10,20)$. Also, isolates of VCG2B were subdivided into two subgroups (VCG2Ba and VCG2Br) based on complementation to reference isolates (20). VCG2Br isolates were defined by the positive complementation of nitratenonutilizing (nit) mutants of tested isolates with reference strains from the international Ohio Agricultural Research and Development Center (OARDC) and Israel $(26,39)$. Conversely, VCG2Ba isolates were characterized by positive complementation of nit 1 mutants of tested isolates with nit mutants of VCG2B isolates from 
artichoke but failed to establish positive complementation with VCG2B reference strains from the international OARDC and Israel (20).

The objectives of this study were to (i) comparatively determine the host range of $V$. dahliae isolates from artichoke and other vegetable crops commonly grown in eastern-central Spain and (ii) determine the genetic variation among those isolates that may reveal any association occurring among host source, VCG, and virulence.

\section{MATERIALS AND METHODS}

$V$. dahliae isolates. Eighteen monoconidial $V$. dahliae isolates collected from vegetable production areas of easterncentral Spain were used in this study (Table 1). VCGs of artichoke isolates were determined in an earlier study by JiménezDíaz et al. (20). VCG typing of nonartichoke isolates was performed by complementation tests of nit mutants using international reference isolates as previously described (25). Artichoke isolates were selected to represent the VCG diversity identified in the Comunidad Valenciana region (20). Non-artichoke isolates were from vegetable crops representative of a wide diversity of commonly grown host species that can be used in rotations with artichoke in the area of the study (Table 1). Isolates were stored in a $15 \%$ glycerol solution at $-80^{\circ} \mathrm{C}$ in $1.5-\mathrm{ml}$ cryovials in the culture collection of the Grupo de Investigación en Hongos Fitopatógenos, Instituto Agroforestal Mediterráneo, Valencia.

DNA extraction and specific PCR assay. DNA was extracted from mycelia of 7-day-old cultures of $V$. dahliae isolates grown in potato-dextrose broth (SigmaAldrich, St. Louis) incubated at room temperature on an orbital shaker. Approximately $20 \mathrm{mg}$ of freeze-dried mycelium was ground to a fine powder with a sterile mortar and pestle. DNA was extracted from ground mycelia using the E.Z.N.A. Plant DNA Kit (Omega Bio-Tek, USA). DNA concentration was determined by comparison of different dilutions of samples with the molecular marker Lambda DNA (New England Biolabs, Ipswich, MA). V. dahliae isolates were characterized by duplex- or multiplex-PCR assays using several primer pairs as previously described (10,30). Primer pair DB19/DB22 (9) yields V. dahliae-specific polymorphic DNA bands of 539 or $523 \mathrm{bp}$ (30). The primer pairs INTD2f/INTD2 $r$ and INTND2f/INTND2r produced PCR markers of 462 and $824 \mathrm{bp}$, previously associated with the cotton- and olive-defoliating (D) and -nondefoliating (ND) $V$. dahliae pathotypes, respectively (30-32). In contrast, primer pair DB19/espdef01 amplifies a 334-bp marker present in D isolates as well as in some ND isolates of VCG1B and VCG2B $(10,11)$.

Amplification of polymorphic markers and sequencing. Four simple- sequence repeats (SSRs) and seven previously developed polymorphic sequences (3) were used to characterize diversity of $V$. dahliae isolates in this study (Table 2). PCR reaction mixtures $(25 \mu \mathrm{l})$ contained $2.5 \mu \mathrm{l}$ of $10 \times$ standard buffer $(15 \mathrm{mM}$ of $\left.\mathrm{MgCl}_{2}\right)$ (Gene Choice, Frederick, MD) $0.25 \mu \mathrm{M}$ each primer (Table 2) (Nucleic Acid Facility, Penn State University), 250 $\mu \mathrm{M}$ each dNTP, $1.25 \mathrm{U}$ of Taq DNA polymerase (Gene Choice), and 10 to $50 \mathrm{ng}$ of template DNA. The initial denaturation step $\left(94^{\circ} \mathrm{C}, 4 \mathrm{~min}\right)$ was followed by 40 cycles of denaturation at $94^{\circ} \mathrm{C}$ for $1 \mathrm{~min}$, annealing at $\mathrm{T}_{\mathrm{a}}$ (Table 2) for $1 \mathrm{~min}$, and elongation at $72^{\circ} \mathrm{C}$ for $1 \mathrm{~min}$, with a final elongation step at $72^{\circ} \mathrm{C}$ for $6 \mathrm{~min}$. Amplifications were performed on an Mastercycle ${ }^{\circledR}$ ep (Eppendorf AG, Hamburg, Germany). Microsatellite alleles were separated on $6 \%$ polyacrylamide gels in $0.5 \times$ Trisborate-EDTA (TBE) buffer and visualized with UV light after ethidium bromide staining. A 25-bp ladder (Invitrogen, Carlsbad, CA) was used to estimate molecular weight of PCR products. Allele sizes and variation of repeats were also assessed by sequence analysis of amplified SSR loci and polymorphic sequences. Purified amplicons were sequenced in both directions using the primers, and sequences of alleles at each locus were aligned and compared using Sequencher v. 4.7 software (Gene Codes, Ann Arbor, MI).

Combined datasets of SSR and polymorphic sequences were developed by assigning simple number codes to each allele per locus for all isolates. Cluster analysis was done using simple matching coefficient by the unweighted pair-group method using arithmetic averages (UPGMA). Calculations were performed using SIMQUAL and SAHN programs of the software package NTSYS-pc (version 2.02j; Exeter Software, Setauket, NY).

Pathogenicity tests. Two experiments (I and II) were performed to test the 18 selected $V$. dahliae isolates (Table 1) for virulence on artichoke cv. Madrigal and the following cultivars of 11 vegetable crop species commonly grown in easterncentral Spain in rotation with artichoke: cardoon (Cynara cardunculus var. cardunculus cv. Blanco Lleno Mejorado), cauliflower (Brassica oleracea cv. Bola de Nieve $\mathrm{X}$ ), cucumber (Cucumis sativus cv. Negrito), eggplant (Solanum melongena cv. Black Beauty), lettuce (Lactuca sativa cv. Romana Larga Rubia), muskmelon (Cucumis melo cv. Sancho), pepper (Capsicum annuum cv. Dulce de España), potato ( $S$. tuberosum cv. Spunta), pumpkin (Cucurbita pepo cv. Dulce de Horno), tomato (S. lycopersicum cv. Marmandino), and watermelon (Citrullus lanatus cv. Dulce Maravilla). Certified seed of these Verticillium wilt nonresistant cultivars were obtained from commercial seed companies. Experiment I included $12 \mathrm{~V}$. dahliae isolates from artichoke representative of the VCG diversity found among artichoke isolates in the Comunidad Valenci-

Table 1. Isolates of Verticillium dahliae used in this study, listed by host source, geographic origin, vegetative compatibility group (VCG), and molecular marker

\begin{tabular}{lllllll}
\hline & & & & \multicolumn{3}{c}{ Molecular marker (bp) $^{\mathbf{a}}$} \\
\cline { 5 - 7 } Isolate & Host & Origin (province) & VCG $^{\mathbf{b}}$ & $\mathbf{3 3 4}$ (D) & $\mathbf{8 2 4}$ (ND) & $\mathbf{4 6 2}$ (D) \\
\hline V403 & Artichoke & Valencia & 1A & + & - & + \\
V404 & Artichoke & Valencia & 2A & - & + & - \\
V542 & Artichoke & Alicante & 2A & - & + & - \\
V536 & Artichoke & Castellón & 2Br & - & + & - \\
V549 & Artichoke & Valencia & 2Br & + & - & - \\
V593 & Artichoke & Alicante & 2Br & - & + & - \\
V613 & Artichoke & Castellón & 2Br & + & - & - \\
V574 & Artichoke & Alicante & 2Ba & + & - & - \\
V675 & Artichoke & Valencia & 2Ba & + & - & - \\
V684 & Artichoke & Valencia & 4B & - & + & - \\
V687 & Artichoke & Valencia & 4B & - & + & - \\
V547 & Artichoke & Alicante & HSI & + & - & - \\
V2 & Watermelon & Valencia & 2A & - & + & - \\
V10 & Pumpkin & Valencia & 2A & - & + \\
V20 & Muskmelon & Castellón & 2A & - & + \\
V25 & Tomato & Valencia & 2A & - & + & - \\
V61 & Potato & Alicante & 4B & - & + \\
V158 & Eggplant & Valencia & 4B & - & + \\
\hline
\end{tabular}

a Amplicons produced in polymerase chain reaction assays using primer sets DB19/DB22/espdef01 (334 bp), INTD2f/INTD2r (462 bp), and INTND2f/INTND2r (824 bp). Amplicons of 334 and 462 bp were previously associated with the cotton-defoliating pathotype, and an amplicon of 824 bp with the cotton-nondefoliating pathotype $(10,30)$. $\mathrm{D}=$ defoliating, $\mathrm{ND}=$ nondefoliating, $+=$ positive amplification, and $-=$ negative amplification.

b VCG2Br is defined by positive complementation of nitrate-nonutilizing (nit) mutants of the tested isolates with the complementary mutants of international Ohio Agricultural Research and Development Center reference and Israeli tester strains $(25,39)$. VCG2Ba is defined by positive complementation of nit 1 mutants of the tested isolates with selected NitM mutants of isolates from artichoke that previously had been assigned to VCG2Br (20). Isolates assigned to VCG2Ba failed to establish positive complementation with nit mutants of the international reference and Israeli tester strains. HSI = heterokaryon self incompatible. 
ana region (20). In experiment II, six $V$. dahliae isolates from different vegetable species grown in the area of study were tested and the artichoke V593 isolate representative of the predominant VCG, VCG2B, was included for comparison (Table 1).
In the two experiments, plants were inoculated by the root-dip inoculation method. Surface-disinfested ( $1 \% \mathrm{NaClO}, 2$ $\mathrm{min})$, germinated seed were sown in trays filled with a sterile (autoclaved twice, $120^{\circ} \mathrm{C}$ for $30 \mathrm{~min}$ ) potting mixture (peat/sand, 2:1, vol/vol). Plants were grown in a greenhouse at 20 to $25^{\circ} \mathrm{C}$ until inoculation (two to three true leaves). Inocula were obtained from 3- to 4-week-old cultures on potato-dextrose agar (PDA) (Biokar Diagnostics, Beauvais, France) by flooding them with sterile distilled water and scraping their surface with a sterile

Table 2. Polymorphic molecular markers used to characterize Verticillium dahliae isolates

\begin{tabular}{|c|c|c|c|c|c|}
\hline Locus $^{\mathbf{a}}$ & Primer sequence $\left(5^{\prime}-3^{\prime}\right)$ & $\mathbf{T}_{\mathbf{a}}\left({ }^{\circ} \mathbf{C}\right)^{\mathbf{b}}$ & Size range (bp) & SNP location and type ${ }^{c}$ & $\mathbf{N a}^{\mathbf{d}}$ \\
\hline \multirow[t]{2}{*}{ VdSSR1 } & F: TTGATCTAGGAAAGCGCATGAC & 55 & $120-128$ & - & 2 \\
\hline & R: CCAGGCAACAATGCAGACA & & & $\ldots$ & \\
\hline \multirow[t]{2}{*}{ VdSSR2 } & F: CCCCGACCTCTCTTCTTTCTAT & 47 & $245-260$ & - & 4 \\
\hline & R: AGCAGAATCACTCATAGGGTGC & & $\ldots$ & $\ldots$ & $\ldots$ \\
\hline \multirow[t]{2}{*}{ VdSSR4 } & F: TCAGAACCGAAGTAACCAA & 47 & $222-224$ & - & 2 \\
\hline & R: GAATCACGCTCCTTCACGGTA & & & $\ldots$ & \\
\hline \multirow[t]{2}{*}{ VdSSR5 } & F: GCAGGGGGTGGCCTCAGCACT & 59 & $217-224$ & - & 2 \\
\hline & R: CGCAGGCATGCCTGGGTGTG & & & & \\
\hline \multirow[t]{2}{*}{ VdSNP1 } & F: TGACACTGAAAAGGATACACCG & 55 & - & 78 C/G; 98 C/T; 181 C/T; 189 T/C; 222 G/C; 292 A/T; & 4 \\
\hline & R: TGGAACACCCATAAGACAACTG & & $\ldots$ & & 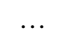 \\
\hline \multirow[t]{2}{*}{ VdSNP2 } & F: GATCATGAAGCGAGTGCGAAGAAC & 59 & - & $328 \mathrm{C} / \mathrm{T} ; 329$ A/G; 334 G/C;348 C/G; 386 T/G & 8 \\
\hline & R: TTGGGGCGTGTGGAAAGGAT & & $\ldots$ & $\ldots$ & \\
\hline \multirow[t]{2}{*}{ VdSNP3 } & F: TGCGCAGCGAACAGAGAC & 59 & - & $80 \mathrm{C} / \mathrm{T} ; 313 \mathrm{~T} / \mathrm{C}$ & 3 \\
\hline & R: CTAAGCCACCCAGCAACACA & & $\ldots$ & $\ldots$ & $\ldots$ \\
\hline \multirow[t]{2}{*}{ VdSNP4 } & F: GAAGGCGCTCCACCCAGTCGTC & 50 & - & $288 \mathrm{~A} / \mathrm{G} ; 289-/ \mathrm{G}$ & 3 \\
\hline & R: GCTAATCGCCCCGTCGCAACA & & $\ldots$ & & $\ldots$ \\
\hline \multirow[t]{2}{*}{ VdSNP5 } & F: ACGGGGGATGGGTGTGAT & 59 & - & $223 \mathrm{~T} / \mathrm{A}$ & 2 \\
\hline & R: TTCTGGCAAGTTTGACATGACTG & & $\ldots$ & $\ldots$ & $\ldots$ \\
\hline \multirow[t]{2}{*}{ VdSNP6 } & F: GCGGCGGCATGCATCACCTC & 59 & - & $204 \mathrm{~A} / \mathrm{T}$ & 2 \\
\hline & R: CCATGGCCTCGGGCGTTCG & & $\ldots$ & & $\ldots$ \\
\hline \multirow[t]{2}{*}{ VdSNP7 } & F: TCAGCTGCGCAACTGCTCAA & 55 & - & $82 \mathrm{C} /$ - $109 \mathrm{~T} / \mathrm{C} ; 113 \mathrm{~A} / \mathrm{T}$ & 3 \\
\hline & R: TCACCGCTTTCCGCTACTACCTT & $\ldots$ & $\ldots$ & $\ldots$ & $\ldots$ \\
\hline
\end{tabular}

a VSSR codes, microsatellite markers; VSNP codes, polymorphic sequences.

${ }^{\mathrm{b}} \mathrm{T}_{\mathrm{a}}$, annealing temperature used in polymerase chain reaction amplifications.

${ }^{\mathrm{c}}$ Nucleotide position and changes in the GenBank accessioned sequence; -, gap in the nucleotide sequence.

d Number of alleles observed.

VCGs Clusters

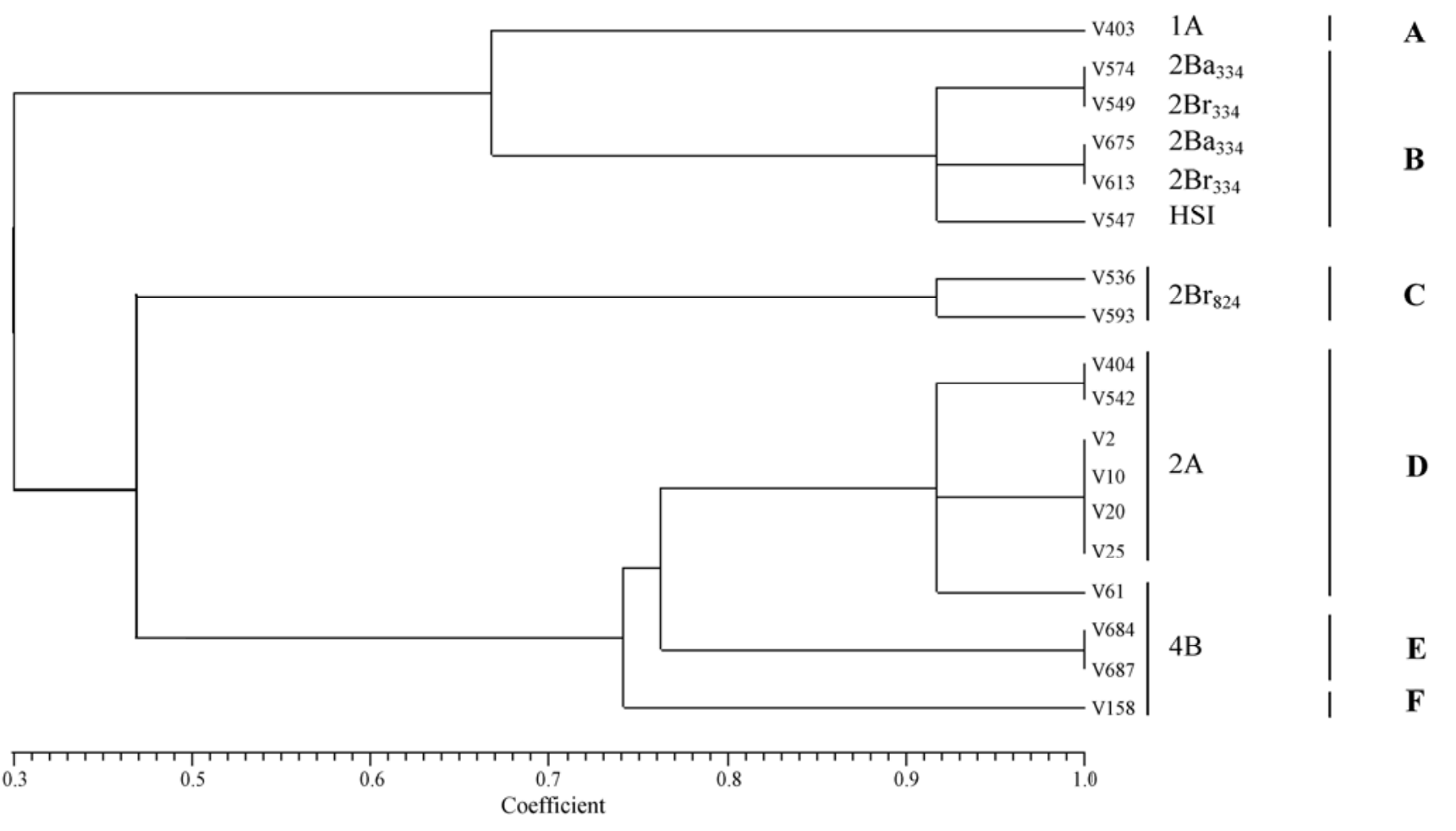

Fig. 1. Dendrogram of 18 Verticillium dahliae isolates from artichoke and other vegetable crops based on cluster analysis of the simple matching similarity coefficient by unweighted pair-group method using arithmetic averages (UPGMA) of the sequence variations detected by four microsatellite markers and seven polymorphic sequences. Artichoke isolates: V403, V574, V549, V675, V613, V547, V404, V542, V684, V687, V536, and V593. Watermelon isolate: V2. Pumpkin isolate: V10. Muskmelon isolate: V20. Tomato isolate: V25. Potato isolate: V61. Eggplant isolate: V158. 
spatula. Inoculum suspensions were filtered through sterile cheesecloth and the conidial concentration in the filtrate was adjusted to $10^{6}$ conidia $\mathrm{ml}^{-1}$ for each isolate. Plants were uprooted from the trays and their roots washed thoroughly under tap water to remove substrate residues, slightly trimmed, and dipped for $10 \mathrm{~min}$ in the conidia suspension of an isolate. Noninoculated control plants were treated the same as the inoculated ones but were dipped in sterile distilled water. Inoculated and control plants were transplanted into 12-cm-diameter plastic pots filled with the sterile potting mixture (one plant per pot) and incubated at the same conditions described above in the greenhouse for 1 month. There were 10 replicated plants for each isolate-cultivar combination in the experiments.

Disease reactions were assessed 1 month after inoculation by the severity of symptoms in individual plants scored on a 1-to-6 scale according to percentage of affected tissue $(1=$ no symptoms; $2=1$ to $25,3=26$ to $50,4=51$ to 75 , and $5=76$ to $100 \%$ of tissue affected; and $6=$ dead plant). Symptoms included chlorosis, defoliation, stunting, and wilting. At the end of the experiments, isolations were made from symptomatic and nonsymptomatic plants to confirm infection and colonization by the pathogen. Plant shoots were surface disinfested ( $1 \% \mathrm{NaClO}, 2 \mathrm{~min})$ and small internal fragments of vascular tissue were plated onto PDA supplemented with streptomycin sulfate (PDAS) at $0.5 \mathrm{mg} \mathrm{ml}^{-1}$. Cultures were incubated and $V$. dahliae colonies identified as described previously (4).

Statistical analysis. Experiments I and II consisted of a factorial treatment design ( $V$. dahliae isolates $\times$ host cultivars) with 10 replicates, each one consisting of a single potted plant, in a complete randomized design. The experiments were repeated once. A two-tailed $F$ test indicated that there was no heterogeneity of variances between the two repetitions of each experiment, allowing data for each treatment to be combined for statistical analyses. Combined datasets were analyzed using a nonparametric procedure for the analysis of ordinal data in factorial experiments $(8,42)$. The overall effect of Verticillium isolates and VCGs on disease reaction on each inoculated host cultivar was determined by the analysis of variance type statistic of ranked data. The PROC mixed procedure in SAS (version 9.0; SAS Institute, Cary, NC) was used to generate relative effects (REs), and the LD_CI macro was used to generate $95 \%$ confidence intervals $(8,42)$. RE values are generated by the equation: $\mathrm{RE}=(R-0.5) / N$; where $R$ is the mean treatment ranking and $N$ is the total number of observations in the analysis. Linear single-degree-of-freedom contrasts were computed to test the effect of selected experimental treatment combinations (18).

\section{RESULTS}

Vegetative compatibility of $V$. dahliae isolates. Of the six non-artichoke $V$. dahliae isolates characterized to VCG in this study, isolates from watermelon (V2), pumpkin (V10), muskmelon (V20), and tomato (V25) were assigned to VCG2A. Isolates from potato (V61) and eggplant (V158) were assigned to VCG4B. Isolate V61 formed weak complementation with the VCG4B reference isolate.

Molecular characterization of $\mathbf{V}$. dahliae isolates by specific PCR, SSR, and polymorphic sequences analyses. All 18 $V$. dahliae isolates used in this study amplified the species-specific 539- or 523-bp polymorphic DNA bands in PCR assays using the DB19/DB22 primer pair. PCR assays of isolates using primer pairs DB19/espdef01 (334-bp amplicon), INTD2f/INTD2r (462-bp amplicon), and INTND2f/INTND2r (824-bp amplicon) produced one of the following patterns of PCR products: $334(+), 824(-), 462(+)$; $334(-), 824(+), 462(-)$; and $334(+), 824$ $(-), 462(-)$ (Table 1). The only artichoke isolate representing VCG1A amplified the 334- and the 462-bp DNA fragments. Isolates assigned to VCG2A and VCG4B amplified the 824-bp marker regardless of host source. Artichoke isolates of VCG2Br amplified either the 824-bp marker (designated as VCG2Br $\mathrm{V}_{824}$ ) or the 334-bp marker (designated as $\mathrm{VCG} 2 \mathrm{Br}_{334}$ ). However, artichoke isolates of VCG2Ba amplified the 334-bp marker (designated as VCG2 $\mathrm{Ba}_{334}$ ) as well as the HSI isolate from artichoke.

Based on the four SSR and seven polymorphic sequences in the 18 isolates, there was a total of 35 alleles (Table 2). Loci produced between two and eight alleles.

Table 3. Median $(\mathrm{M})$ and mean rankings $(R)$ calculated for the severity of Verticillium wilt symptoms on artichoke, cardoon, eggplant, muskmelon, potato, tomato, and watermelon caused by isolates of Verticillium dahliae from artichoke of different vegetative compatibility groups (VCGs) ${ }^{\mathrm{a}}$

\begin{tabular}{|c|c|c|c|c|c|c|c|c|c|c|c|c|c|c|}
\hline \multirow[b]{2}{*}{ VCG, isolates ${ }^{b}$} & \multicolumn{2}{|c|}{ Artichoke } & \multicolumn{2}{|c|}{ Cardoon } & \multicolumn{2}{|c|}{ Eggplant } & \multicolumn{2}{|c|}{ Muskmelon } & \multicolumn{2}{|c|}{ Potato } & \multicolumn{2}{|c|}{ Tomato } & \multicolumn{2}{|c|}{ Watermelon } \\
\hline & $\mathbf{M}$ & $\boldsymbol{R}$ & M & $\boldsymbol{R}$ & M & $\boldsymbol{R}$ & M & $\boldsymbol{R}$ & $\mathbf{M}$ & $\boldsymbol{R}$ & $\mathbf{M}$ & $\boldsymbol{R}$ & M & $\boldsymbol{R}$ \\
\hline Control & 1.0 & 5.5 & 1.0 & 12.6 & 1.0 & 9.5 & 1.0 & 33.0 & 1.0 & 25.5 & 1.0 & 43.5 & 1.0 & 10.5 \\
\hline $1 \mathrm{~A}, \mathrm{~V} 403$ & 5.4 & 81.0 & 4.1 & 95.4 & 1.8 & 25.4 & 1.2 & 42.4 & 1.0 & 25.5 & 1.1 & 49.7 & 4.9 & 90.3 \\
\hline 2A, V404 and V542 & 4.3 & 49.9 & 2.3 & 48.8 & 3.0 & 51.3 & 2.0 & 67.6 & 2.0 & 64.3 & 2.4 & 90.8 & 4.0 & 66.6 \\
\hline $2 \mathrm{Ba}_{334}, \mathrm{~V} 574$ and V675 & 4.8 & 59.6 & 2.5 & 54.4 & 2.6 & 43.3 & 2.8 & 91.7 & 2.1 & 67.8 & 1.3 & 60.3 & 4.6 & 76.2 \\
\hline $2 \mathrm{Br}_{334}, \mathrm{~V} 549$ and $\mathrm{V} 613$ & 4.3 & 48.8 & 2.4 & 51.2 & 4.0 & 77.5 & 3.0 & 92.0 & 2.3 & 79.7 & 1.6 & 75.9 & 3.8 & 54.9 \\
\hline $2 \mathrm{Br}_{824}, \mathrm{~V} 536$ and V593 & 5.9 & 101.6 & 4.4 & 100.0 & 5.0 & 109.5 & 1.4 & 48.9 & 2.3 & 76.2 & 1.2 & 53.1 & 4.8 & 87.9 \\
\hline 4B, V684 and V687 & 4.7 & 56.8 & 2.4 & 49.5 & 4.0 & 81.3 & 1.6 & 53.3 & 1.9 & 63.9 & 1.1 & 49.8 & 2.8 & 45.6 \\
\hline HSI, V547 & 3.9 & 32.7 & 3.0 & 65.4 & 4.4 & 90.5 & 2.0 & 69.0 & 1.6 & 49.8 & 1.0 & 43.5 & 4.3 & 67.8 \\
\hline \multicolumn{15}{|l|}{ Contrast $(P)^{\mathrm{c}}$} \\
\hline $1 \mathrm{~A}$ vs all & \multicolumn{2}{|c|}{0.0013} & \multicolumn{2}{|c|}{$<0.0001$} & \multicolumn{2}{|c|}{$<0.0001$} & \multicolumn{2}{|c|}{0.0001} & \multicolumn{2}{|c|}{$<0.0001$} & \multicolumn{2}{|c|}{0.0614} & \multicolumn{2}{|c|}{$<0.0001$} \\
\hline 2A vs all & \multicolumn{2}{|c|}{0.0618} & \multicolumn{2}{|c|}{0.0020} & \multicolumn{2}{|c|}{$<0.0001$} & \multicolumn{2}{|c|}{0.8730} & \multicolumn{2}{|c|}{0.6699} & \multicolumn{2}{|c|}{$<0.0001$} & \multicolumn{2}{|c|}{0.6327} \\
\hline $2 \mathrm{Ba}_{334} \mathrm{vs}$ all & \multirow{2}{*}{\multicolumn{2}{|c|}{$\begin{array}{l}0.6052 \\
0.0162\end{array}$}} & \multicolumn{2}{|c|}{0.0088} & \multicolumn{2}{|c|}{$<0.0001$} & \multicolumn{2}{|c|}{$<0.0001$} & \multicolumn{2}{|c|}{0.3647} & \multicolumn{2}{|c|}{0.9785} & \multicolumn{2}{|c|}{0.2265} \\
\hline $2 \mathrm{Br}_{334} \mathrm{vs}$ all & & & & 025 & & & & & & & & & & \\
\hline $2 \mathrm{Br}_{824} \mathrm{vs}$ all & $<0$ & & $<0$. & 001 & $<0.0$ & & & & & & & & & \\
\hline 4B vs all & & & & 415 & & & & & & & & & & \\
\hline HSI vs all & $<0$ & & & 227 & & & & & & & $<0.0$ & & & \\
\hline $2 \mathrm{~A}$ vs $4 \mathrm{~B}$ & & & & 508 & & 05 & & & & & $<0.0$ & & & \\
\hline HSI vs $2 \mathrm{Br}_{334}, 2 \mathrm{Ba}_{334}$ & & & & 763 & & & & & & & $<0.0$ & & & \\
\hline $2 \mathrm{Ba}_{334}$ vs $2 \mathrm{Br}_{334}, 2 \mathrm{Br}_{824}$ & & & & 002 & $<0$. & & & & & & & & & \\
\hline $2 \mathrm{Ba}_{334}$ vs $2 \mathrm{Br}_{334}$ & & & & 293 & $<0.0$ & & & & & & & & & \\
\hline $2 \mathrm{Br}_{824}$ vs $2 \mathrm{Br}_{334}, 2 \mathrm{Ba}_{334}$ & $<0$ & & $<0$. & 001 & $<0$ & & $<0$. & & & & & & & \\
\hline
\end{tabular}

${ }^{a}$ For median disease rating (M), severity of Verticillium wilt symptoms was assessed visually according to the percentage of foliar tissue affected (foliar symptoms including chlorosis, defoliation, stunting, and wilting) using an ordinal 1-to-6 rating scale in which $1=$ no symptoms; $2=1$ to $25,3=26$ to 50,4 $=51$ to 75 , and $5=76$ to $100 \%$ of foliar tissue affected; and $6=$ dead plant.

${ }^{\mathrm{b}}$ VCG of the isolates inoculated. Isolates were inoculated on the different species by root immersion; roots of control plants were immersed in sterile distilled water. HSI = heterokaryon self incompatible.

${ }^{\mathrm{c}}$ Linear single-degree-of-freedom contrast computed to test the effect of selected treatment combinations. Probability for the $t$ statistic of linear single-degree-of-freedom contrasts, significance level $P<0.05$. 
UPGMA analysis of the SSR and polymorphic sequence data sets separated the isolates into six clusters (designated A, B, $\mathrm{C}, \mathrm{D}, \mathrm{E}$, and F) based on similarity coefficient values of approximately 0.30 to 0.75 , which correlated with VCGs of isolates (Fig. 1). Cluster A comprised the only isolate representative of VCG1A. Cluster B included five VCG2B isolates from artichoke that amplified the 334-bp marker and the single HSI isolate. Cluster $\mathrm{C}$ included isolates in VCG2B that amplified the 824-bp marker. Cluster D contained all VCG2A isolates from artichoke and other hosts and one potato isolate in VCG4B (V61). Cluster $\mathrm{E}$ contained isolates in VCG4B from artichoke that shared a similarity coefficient of 0.77 to 1 . Finally, the eggplant isolate V158 in VCG4B was separated from the rest in cluster $\mathrm{F}$.

Pathogenicity of $\mathrm{V}$. dahliae isolates. All $18 \mathrm{~V}$. dahliae isolates were pathogenic on artichoke, cardoon, eggplant, and watermelon as indicated by mean symptom severity rankings significantly greater than those in the noninoculated controls $(P<$ 0.05 ) but differed in virulence on specific hosts. Conversely, only some of the isolates in the study were pathogenic to muskmelon, potato, and tomato (Tables 3 and 4; Figs. 2 and 3). No symptoms developed on inoculated cauliflower, cucumber, lettuce, or pepper plants (data not shown).
Therefore, all 18 isolates were considered nonpathogenic to these species. $V$. dahliae was isolated from symptomatic plants of susceptible species and only occasionally recovered from nonsymptomatic plants of cauliflower, cucumber, pepper, and pumpkin.

Median and mean rankings for the severity of symptoms caused by artichoke isolates on different hosts in experiment I, as well as results of linear single-degreeof-freedom contrasts computed to test the effect of selected treatment combinations, are shown in Table 3. Estimated relative effects and confidence intervals are represented in Figure 2. Significant differences in mean symptom severity rankings were observed among hosts $(P<0.0001)$, between VCGs of isolates $(P<0.0001)$, and for the VCG-host interaction $(P<0.0001)$ in experiment I.

Collectively, artichoke $V$. dahliae isolates of $\mathrm{VCG} 1 \mathrm{~A}$ and $\mathrm{VCG} 2 \mathrm{Br}_{824}$ were significantly more virulent to artichoke, cardoon, and watermelon than those in other VCGs, as indicated by mean symptom severity rankings (Table 3 ). Isolates of $\mathrm{VCG}_{2} \mathrm{Br}_{824}$ and the HSI isolate were significantly more virulent on eggplant than those in the other VCGs (Table 3).

Among artichoke isolates of VCG2B, those in $\mathrm{VCG}_{2} \mathrm{Br}_{824}$, as a group, were significantly more virulent on artichoke, car- doon, and eggplant $(P<0.0001)$ than isolates in $\mathrm{VCG}_{2} \mathrm{Br}_{334}$ and $\mathrm{VCG} 2 \mathrm{Ba}_{334}$ (Table 3 ; Fig. 2). Conversely, isolates in VCG2 $\mathrm{Ba}_{334}$ and $\mathrm{VCG} 2 \mathrm{Br}_{334}$ were significantly more virulent on muskmelon than those in the other VCGs (Table 3). However, artichoke isolates in VCG1A (V403),

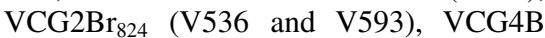
(V684 and V687), and the HSI isolate (V547) were not pathogenic to muskmelon (Table 3; Fig. 2). Isolates of $\mathrm{VCG}^{2} \mathrm{Br}_{334}(P$ $=0.0025)$ and $\mathrm{VCG}_{2} \mathrm{Br}_{824}(P=0.0080)$ were significantly more virulent on potato than those in the other VCGs but isolates in VCG1A was not pathogenic (Table 3). Isolates of VCG2A and VCG2Br $\mathrm{Br}_{334}$ were significantly more virulent on tomato than those in other VCGs, which were considered not pathogenic to tomato (Table 3; Fig. 2). VCG2B isolates that amplified the 334-bp marker (VCG2Br 334 and VCG2Ba ${ }_{334}$ ) and the HSI isolate were compared for virulence because they grouped together in cluster B (Fig. 1). Significant differences were detected among those VCG subgroups in virulence to all hosts except for cardoon, muskmelon, and watermelon (Table 3).

Median and mean rankings for the severity of symptoms caused by isolates on different hosts in experiment II, as well as results of linear single-degree-of-freedom contrast, are shown in Table 4. Estimated

Table 4. Median (M) and mean rankings $(R)$ calculated for the severity of Verticillium wilt symptoms on artichoke, cardoon, eggplant, muskmelon, potato, tomato and watermelon caused by isolates of Verticillium dahliae collected from different vegetable crops ${ }^{\mathrm{a}}$

\begin{tabular}{|c|c|c|c|c|c|c|c|c|c|c|c|c|c|c|}
\hline \multirow[b]{2}{*}{ Group, isolates $^{\text {b }}$} & \multicolumn{2}{|c|}{ Artichoke } & \multicolumn{2}{|c|}{ Cardoon } & \multicolumn{2}{|c|}{ Eggplant } & \multicolumn{2}{|c|}{ Muskmelon } & \multicolumn{2}{|c|}{ Potato } & \multicolumn{2}{|c|}{ Tomato } & \multicolumn{2}{|c|}{ Watermelon } \\
\hline & M & $\boldsymbol{R}$ & M & $\boldsymbol{R}$ & M & $\boldsymbol{R}$ & M & $\boldsymbol{R}$ & $\mathbf{M}$ & $\boldsymbol{R}$ & M & $\boldsymbol{R}$ & M & $\boldsymbol{R}$ \\
\hline Control & 1.0 & 5.0 & 1.0 & 6.0 & 1.0 & 5.5 & 1.0 & 28.0 & 1.0 & 13.0 & 1.0 & 27.0 & 1.0 & 9.5 \\
\hline \multicolumn{15}{|l|}{ Cucurbitaceous } \\
\hline V2 & 4.9 & 42.9 & 3.9 & 48.1 & 3.3 & 28.5 & 2.0 & 48.9 & 2.1 & 44.5 & 1.0 & 27.0 & 3.0 & 21.6 \\
\hline V10 & 4.9 & 41.6 & 3.8 & 47.5 & 4.2 & 46.7 & 1.5 & 41.0 & 1.9 & 38.2 & 2.2 & 58.0 & 6.0 & 47.0 \\
\hline V20 & 2.8 & 15.6 & 1.9 & 19.5 & 2.4 & 17.3 & 1.7 & 44.1 & 1.2 & 18.9 & 1.0 & 27.0 & 4.3 & 33.3 \\
\hline \multicolumn{15}{|l|}{ Solanacaceous } \\
\hline V25 & 5.0 & 44.2 & 3.8 & 45.8 & 3.9 & 40.1 & 1.3 & 38.5 & 2.7 & 59.2 & 1.8 & 44.8 & 5.3 & 42.3 \\
\hline V61 & 5.7 & 61.2 & 4.7 & 58.5 & 5.3 & 68.9 & 1.3 & 38.5 & 2.2 & 47.5 & 2.4 & 64.6 & 5.3 & 41.3 \\
\hline V158 & 5.2 & 49.4 & 2.8 & 33.6 & 4.3 & 48.5 & 1.3 & 39.7 & 2.4 & 50.4 & 1.0 & 27.0 & 5.7 & 41.1 \\
\hline \multicolumn{15}{|l|}{ Artichoke } \\
\hline V593 & 5.5 & 56.6 & 3.7 & 46.9 & 5.0 & 65.0 & 1.2 & 32.9 & 1.9 & 39.2 & 1.3 & 35.6 & 4.7 & 35.9 \\
\hline \multicolumn{15}{|l|}{ Contrast $(P)^{\mathrm{c}}$} \\
\hline V2 vs all & \multicolumn{2}{|c|}{0.6695} & \multicolumn{2}{|c|}{0.2871} & \multicolumn{2}{|c|}{$<0.0001$} & \multicolumn{2}{|c|}{0.1959} & \multicolumn{2}{|c|}{0.6627} & \multicolumn{2}{|c|}{$<0.0001$} & \multicolumn{2}{|c|}{0.0017} \\
\hline V10 vs all & \multicolumn{2}{|c|}{0.4464} & \multicolumn{2}{|c|}{0.4214} & \multicolumn{2}{|c|}{0.5854} & \multicolumn{2}{|c|}{0.9302} & \multicolumn{2}{|c|}{0.4966} & \multicolumn{2}{|c|}{0.0006} & \multicolumn{2}{|c|}{$<0.0001$} \\
\hline V20 vs all & \multicolumn{2}{|c|}{$<0.0001$} & \multicolumn{2}{|c|}{$<0.0001$} & \multicolumn{2}{|c|}{$<0.0001$} & & & $<0$. & & & & & 81 \\
\hline V25 vs all & & & & & & & & & & & & & & 01 \\
\hline V593 vs all & & & & & $<0$ & & & & & & & & & \\
\hline V61 vs all & $<0$. & & $<0$. & & $<0$ & & & & & & & & & 39 \\
\hline V158 vs all & & & & & & & & & & & & & & 199 \\
\hline VCG2A vs VCG4B $^{\mathrm{d}}$ & $<0.0$ & & 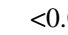 & & $<0$ & & & & $<0$. & & & & & 144 \\
\hline Cucurbitaceous vs solanaceous $\mathrm{e}$ & $<0$. & & & & $<0$. & & & & & & & & & 582 \\
\hline Cucurbitaceous vs artichoke & & & & & $<0$. & & & & & & & & & 174 \\
\hline Solanaceous vs artichoke & & & & & $<0$. & & & & & & & & & 523 \\
\hline
\end{tabular}

${ }^{a}$ For median disease rating (M), severity of Verticillium wilt symptoms was assessed visually according to the percentage of foliar tissue affected (foliar symptoms including chlorosis, defoliation, stunting, and wilting) using an ordinal 1-to-6 rating scale in which $1=$ no symptoms; $2=1$ to $25,3=26$ to 50,4 $=51$ to 75 , and $5=76$ to $100 \%$ of foliar tissue affected; and $6=$ dead plant.

b Isolates inoculated grouped by the taxonomic relationship of the isolates' host source. Cucurbitaceous = isolates from watermelon (V2), pumpkin (V10) and muskmelon (V20). Solanaceous = isolates collected from tomato (V25), potato (V61), and eggplant (V158). Artichoke = isolate from artichoke (V593). Isolates were inoculated on the different species by root immersion; roots of control plants were immersed in sterile distilled water.

${ }^{\mathrm{c}}$ Linear single-degree-of-freedom contrast computed to test the effect of selected treatment combinations. Probability for the $t$ statistic of linear single-degree-of-freedom contrasts, significance level $P<0.05$

${ }^{d}$ Linear single-degree-of-freedom contrast of the mean rankings corresponding to isolates in VCG2A (V2, V10, V20, and V25) and VCG4B (V61),

${ }^{\mathrm{e}}$ Linear single-degree-of-freedom contrast of the mean rankings corresponding to groups of isolates based on the taxonomic relationship of the isolates' host source. 
relative effects and confidence intervals are represented in Figure 3. Significant differences in mean symptom severity rankings were observed among hosts $(P<0.0001)$, among isolates differing in host source $(P$
$<0.0001)$, and for the isolate-host interaction $(P<0.0001)$ in experiment II.

The artichoke isolate V593 was significantly $(P=0.0148)$ more virulent on artichoke and eggplant compared with all others isolates (Table 4). Similarly, the pumpkin isolate $\mathrm{V} 10$ was the most virulent isolate on watermelon (Table 4) but it failed to cause disease on pumpkin (data not shown). None of the isolates were
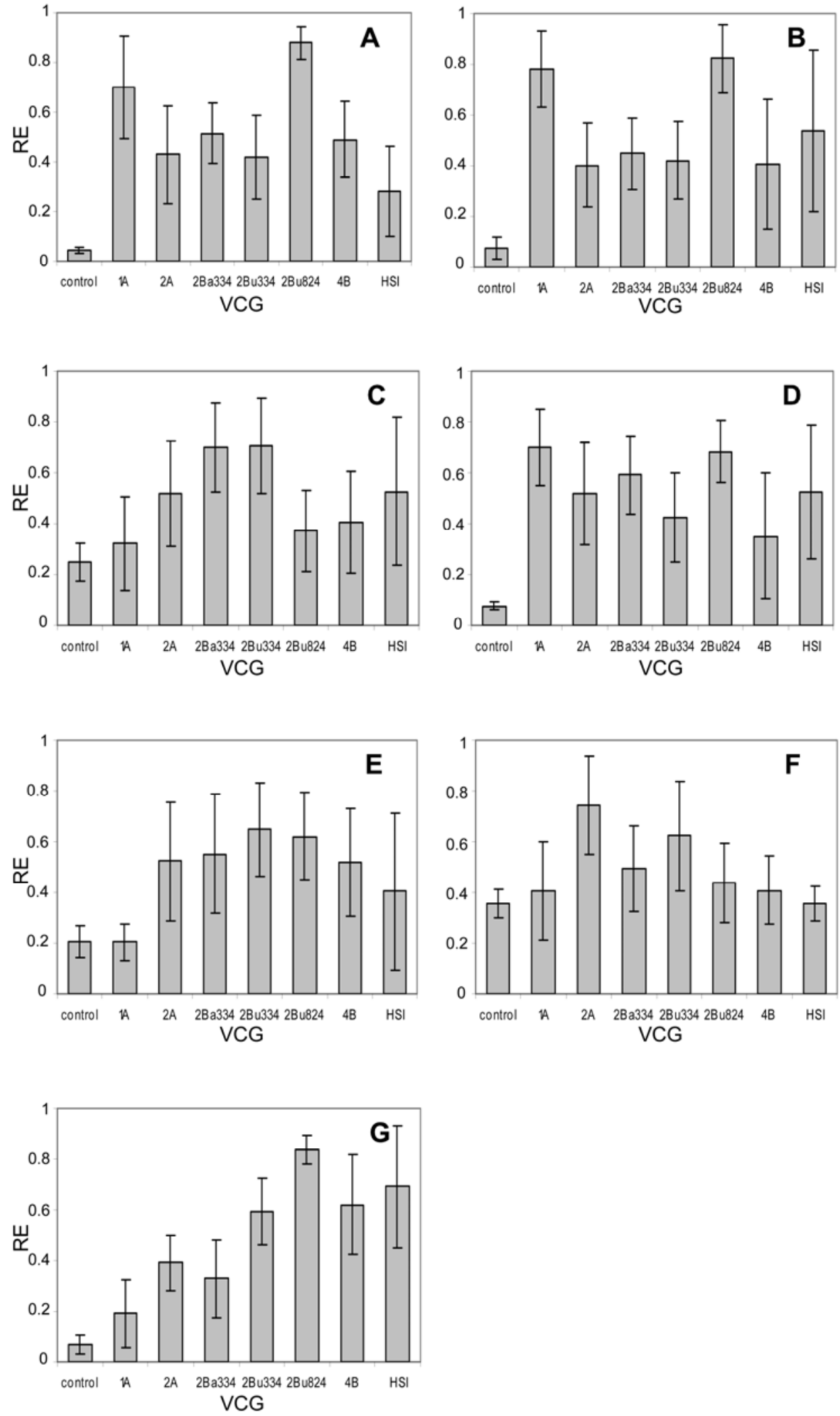

Fig. 2. Estimated relative effects (REs) in experiment I based on the analysis of variance-type statistics of ranked data for the severity of Verticillium wilt symptoms on A, artichoke; $\mathbf{B}$, cardoon; $\mathbf{C}$, muskmelon; D, watermelon; $\mathbf{E}$, potato; $\mathbf{F}$, tomato; and $\mathbf{G}$, eggplant caused by Verticillium dahliae artichoke isolates of vegetative compatibility groups (VCGs) $1 \mathrm{~A}, 2 \mathrm{~A}, 2 \mathrm{Ba}_{334}, 2 \mathrm{Br}_{334}, 2 \mathrm{Br}_{824}, 4 \mathrm{~B}$, and heterokaryon self-incompatible (HSI). Confidence intervals (95\%) for relative effects are represented by vertical lines. 
pathogenic on muskmelon (Table 4; Fig. 3 ), and muskmelon isolate V20 was not pathogenic to potato (Table 4; Fig. 3). The potato isolate V61 was significantly more virulent on artichoke, cardoon, eggplant, and tomato compared with all other isolates (Table 4). Only isolates from pumpkin (V10), tomato (V25), and potato (V61) were pathogenic to tomato (Table 4; Fig. 3).
Isolates in VCG2A (V2, V10, V20, and V25) and VCG4B (V61), which grouped together in cluster $\mathrm{C}$, differed in virulence on all hosts except muskmelon and watermelon (Table 4). A degree of association
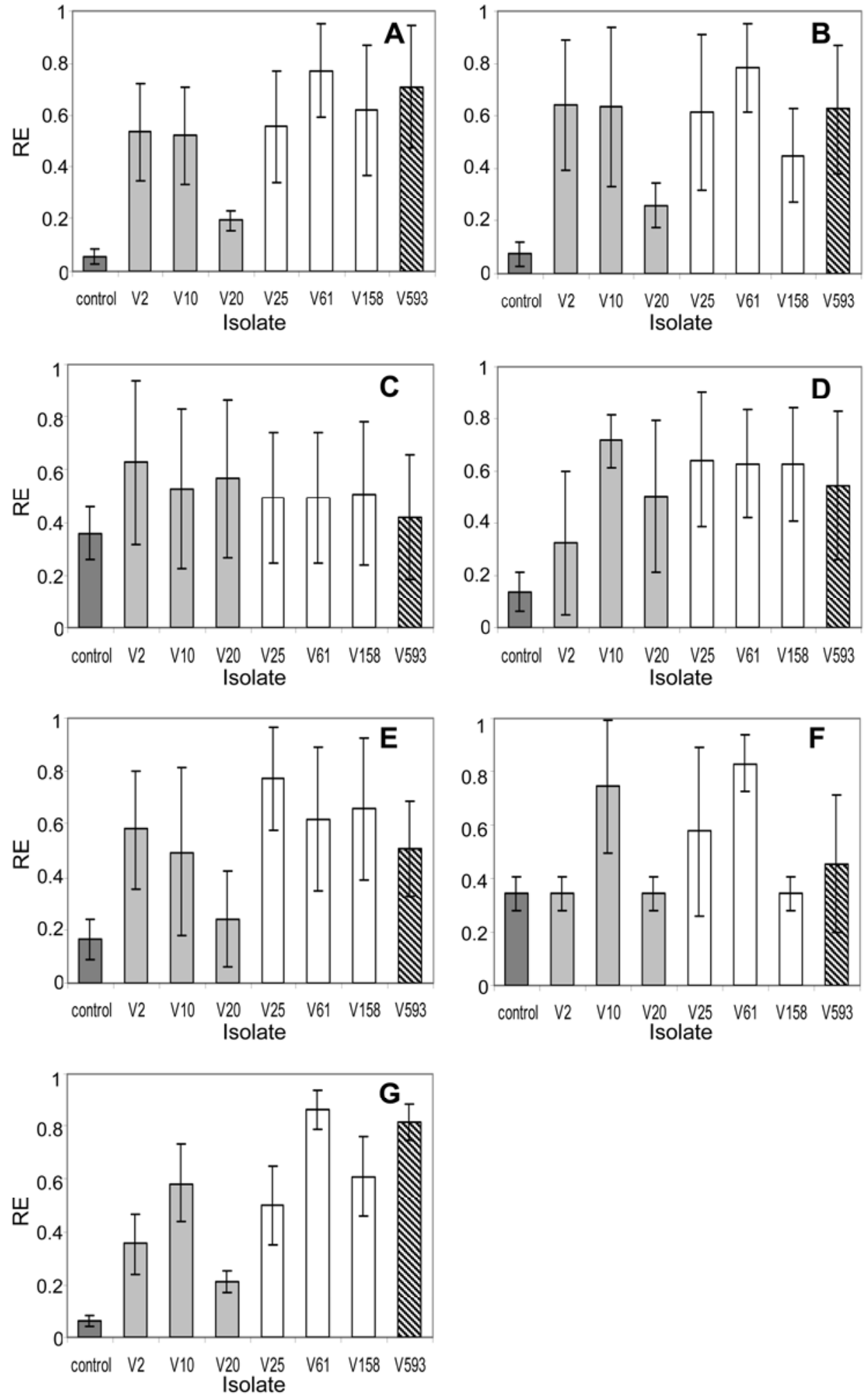

Fig. 3. Estimated relative effects (RE) in experiment II based on the analysis of variance-type statistics of ranked data for the severity of Verticillium wilt symptoms on $\mathbf{A}$, artichoke; $\mathbf{B}$, cardoon; $\mathbf{C}$, muskmelon; D, watermelon; $\mathbf{E}$, potato; $\mathbf{F}$, tomato; and $\mathbf{G}$, eggplant caused by Verticillium dahliae isolates: V2 = watermelon isolate, V10 = pumpkin isolate, V20 = muskmelon isolate, V25 = tomato isolate, V593 = artichoke isolate, V61 = potato isolate, and V158 = eggplant isolate. Confidence intervals $(95 \%)$ for relative marginal effects are represented by vertical lines. Bars are textured according to the taxonomic relationship of the isolates' host source: isolates collected from cucurbitaceous plants (gray-shaded bar), solanaceous plants (white bar), and artichoke (crosshatched bar). 
was found between the taxonomic relationship of host source of isolates and virulence to given hosts. Thus, isolates from solanaceous plants (V25, V61, and V158) were significantly more virulent on potato than all other isolates (Table 4; Fig. 3 ), isolates from cucurbitaceous plants (V2, V10, and V20) were significantly less virulent on artichoke compared with other isolates, and the artichoke isolate V593 was significantly more virulent on eggplant than other isolates (Table 4; Fig. 3).

\section{DISCUSSION}

Genetic and pathogenic characterization of $V$. dahliae isolates in an agricultural region may provide important insights into the epidemiology and management of the diseases they cause. In this study, V. dahliae isolates collected from artichoke and other vegetable species cultivated in eastern-central Spain were characterized by means of molecular markers and virulence to 12 important hosts for that region. We demonstrate that differential virulence occurs among isolates from certain hosts and that differences can be associated with genetic diversity among isolates. Although all isolates caused severe disease symptoms on artichoke, cardoon, eggplant, and watermelon, those from artichoke showed a limited host range and isolates from watermelon, muskmelon, and eggplant were not pathogenic to some of the hosts tested. A previous report demonstrated that eggplant isolates exhibit host specificity and differential virulence on other hosts, whereas isolates from artichoke, potato, tomato, and watermelon did not (7).

Isolates of $V$. dahliae are usually considered to be host adapted rather than host specific, because isolates seem to be most virulent on certain hosts but often have the potential to infect a wide range of hosts (16,38). In general, isolates of $V$. dahliae are highly virulent on the hosts from which they were originally isolated $(7,13,19,38)$. In our study, all isolates were pathogenic on hosts other than the host source. However, our results showed a possible association between the taxonomic relationship of the host source of isolates and their virulence on certain hosts.

Other authors have suggested that host range is more influenced by crop history than the original host source of the isolate (45) or by the VCG of the isolate (48). Several studies demonstrated that VCGs of $V$. dahliae do not appear to be related to pathogenicity of particular host species but there is some correlation with virulence to certain hosts such as VCG4A and potato in the United States (39). In this study, $V$. dahliae isolates from artichoke differed in virulence on certain hosts, and the virulence appeared related to VCG. Thus, artichoke isolates in VCG2A caused severe disease in tomato, which agreed with earlier reports describing isolates in VCG2A as virulent on tomato (46). In our study, the artichoke isolate in VCG1A was not pathogenic to muskmelon and potato but highly virulent on artichoke. In contrast, artichoke isolates in VCG1A were less virulent on the host source than on cotton (20). In previous studies, individual isolates within VCGs varied considerably with respect to virulence $(17,19,43)$. However, there was a consistent relationship between VCG and virulence on the host source, which was reported for artichoke (20) and potato and cotton $(27,43)$.

Artichoke has been described as the cultivated form of cardoon (40). To our knowledge, there are no references about the incidence of Verticillium wilt in cultivated cardoon, and no disease has been observed on cardoon crops grown in fields in the Comunidad Valenciana region of Spain, which is highly infested with $V$. dahliae (M. Berbegal and J. Armengol, unpublished). Therefore, we included cardoon in pathogenicity tests because cardoon germplasm may be a potential source of resistance to $V$. dahliae in artichoke breeding programs. However, our results revealed that cardoon is very susceptible to the pathogen, to an extent similar to artichoke and eggplant $(14,37,38)$.

In strictly asexually reproducing pathogens, such as $V$. dahliae, host-associated differences in neutral molecular markers can be investigated with the assumption that, on particular hosts, associations between loci controlling pathogenicity and neutral molecular loci might emerge (34). Combining neutral molecular markers with pathogenicity assays represents a useful method of studying host specificity in pathogens with broad host ranges. Based on specific PCR markers, VCG2B from artichoke in eastern-central Spain is genetically heterogeneous, and that subgrouping of isolates associated with such heterogeneity correlates with virulence to artichoke and cotton (20). In our study, subgrouping among artichoke isolates in VCG2B based on genetic and molecular differences was also correlated with virulence to different hosts. The pattern of correlation was similar on artichoke, cardoon, and eggplant, to which isolates of VCG2 $\mathrm{Br}_{824}$ were the most virulent. Artichoke isolates of $\mathrm{VCG} 2 \mathrm{Br}_{824}$ were also the most virulent to potato and watermelon.

Qin et al. (36) recently reported the existence of genetically distinct subpopulations of $V$. dahliae adapted to specific hosts but each being cross pathogenic to various crops. Some of the past inconsistencies in the associations between $V$. dahliae isolates and molecular subgroupings $(5,7)$ may have resulted from pathogenicity tests with a limited number of hosts, underestimating the full pathogenic potential of the tested isolates (36).

The correlation between neutral genetic markers and VCGs in V. dahliae isolates from artichoke and other crops has already been demonstrated using AFLPs (10). In the present study, recently developed microsatellite (SSRs) and polymorphic sequences were used to easily characterize molecular variability of $V$. dahliae isolates from artichoke and other vegetable species grown in the Comunidad Valenciana region. Results showed that $V$. dahliae isolates within a VCG shared most of the alleles and could be clearly separated from those in other VCGs regardless of their host source. UPGMA analysis clustered isolates in accordance with their VCG and confirmed molecular heterogeneity of artichoke isolates in VCG2B based on AFLPs and specific PCR markers $(10,20)$. Molecular variability among isolates could be associated with VCG diversity and differential virulence on certain hosts.

Occasionally, weak complementation occurs between strains of different VCGs that indicate transitory functional heterokaryosis before incompatibility is expressed, and suggests that VCGs might not be as completely isolated in genetic terms as previously thought. According to some authors, weak heterokaryon reactions often occur between testers or nit mutant isolates of VCG2 and VCG4 $(21,43)$. In our study, isolates in VCG2A and 4B clustered very closely in the dendrogram and one of the isolates from potato that formed weak complementation reaction with the VCG4B reference isolate grouped with the VCG2A isolates in the same cluster. These results suggest that isolates in VCG2A and VCG4B could be more similar to each other than to isolates of other VCGs. This agrees with results of Collado-Romero et al., who found a similar relationship by AFLP analysis (10).

According to Bhat and Subbarao, results of pathogenicity tests in the greenhouse are predictive of host ranges in the field (7). Therefore, decisions concerning crop rotations in eastern-central Spain can be based on data reported here (20). Moreover, rotation with nonhost crops might reduce the probability for the selection of highly virulent strains of $V$. dahliae favored by monoculture (15). All isolates studied here were nonpathogenic to cauliflower, cucumber, lettuce, pepper, and pumpkin and, thus, their use in rotation with susceptible crops would not likely increase inoculum in the soil. However, recommendations for cropping sequences should be made with caution, and further research on isolates from a wider variety of vegetable crops is needed.

\section{ACKNOWLEDGMENTS}

M. Berbegal was a recipient of an FPU fellowship from the Ministry of Education and Science of Spain (AP2002-3818). We thank A. Vicent for helpful comments on the manuscript prior to submission.

\section{LITERATURE CITED}

1. Armengol, J., Berbegal, M., Giménez-Jaime, A., Romero, S., Beltrán, R., Vicent, A., Ortega, A., and García-Jiménez, J. 2005. Incidence of Verticillium wilt of artichoke in eastern Spain 
and role of inoculum sources on crop infection. Phytoparasitica 33:397-405.

2. Berbegal, M., and Armengol, J. 2009. First report of Verticillium wilt of faba bean caused by Verticillium dahliae in Spain. Plant Dis. 93:432.

3. Berbegal, M., Garzón, C., Ortega, A., Armengol, J., Jiménez-Díaz, R. M., and JiménezGasco, M. M. Development and application of new molecular markers for analysis of genetic diversity in Verticillium dahliae populations. Plant Pathol. In press.

4. Berbegal, M., Ortega, A., García-Jiménez, J., and Armengol, J. 2007. Inoculum densitydisease development relationship in Verticillium wilt of artichoke caused by Verticillium dahliae. Plant Dis. 91:1131-1136.

5. Bhat, R. G., Smith, R. F., Koike, S. T., Wu, B. M., and Subbarao, K. V. 2003. Characterization of Verticillium dahliae isolates and wilt epidemics of pepper. Plant Dis. 87:789-797.

6. Bhat, R. G., and Subbarao, K. V. 1999. First report of Verticillium dahliae causing artichoke wilt in California. Plant Dis. 83:782.

7. Bhat, R. G., and Subbarao, K. V. 1999. Host range specificity in Verticillium dahliae. Phytopathology 89:1218-1225

8. Brunner, E., Domhof, S., and Langer, F. 2002. Nonparametric Analysis of Longitudinal Data in Factorial Experiments. John Wiley \& Sons, New York.

9. Carder, J. H., Morton, A., Tabrett, A. M., and Barbara, D. J. 1994. Detection and differentiation by PCR of subspecific groups within two Verticillium species causing vascular wilts in herbaceous hosts. Pages 91-97 in: Modern Assays for Plant Pathogenic Fungi. A. Schots, F. M. Dewey, and R. Oliver, eds. CAB International, Wallingford, UK.

10. Collado-Romero, M., Mercado-Blanco, J., Olivares-García, C., Valverde-Corredor, A., and Jiménez-Díaz, R. M. 2006. Molecular variability within and among Verticillium dahliae vegetative compatibility groups determined by fluorescent amplified fragment length polymorphism and polymerase chain reaction markers. Phytopathology 96:485-495.

11. Collins, A., Mercado-Blanco, J., Jiménez-Díaz, R. M., Olivares, C., Clewes, E., and Barbara, D. J. 2005. Correlation of molecular markers and biological properties in Verticillium dahliae and the possible origins of some isolates. Plant Pathol. 54:549-557.

12. Chandelier, A., Laurent, F., Dantinne, D., Mariage, L., Etienne, M., and Cavelier, M. 2003. Genetic and molecular characterization of Verticillium dahliae isolates from woody ornamentals in Belgian nurseries. Eur. J. Plant Pathol. 109:943-952.

13. Chang, R. J., and Eastburn, D. M. 1994. Host range of Verticillium dahliae from horseradish and pathogenicity of strains. Plant Dis. 78:503506.

14. Cherrab, M., Serrhini, M. N., and Charest, P. M. 2000. Characterization of Moroccan isolates of Verticillium dahliae Kleb. using RAPD markers. J. Phytopathol. 148:243-249.

15. Davis, J. R., Pavek, J. J., Corsini, D. L., Sorensen, L. H., Schneider, A. T., Everson, D. O., Westermann, D. T., and Huisman, O. C. 1994. Influence of continuous cropping of several potato clones on the epidemiology of Verticillium wilt of potato. Phytopathology 84:207214.

16. Douhan, L. I., and Johnson, D. A. 2001. Vegetative compatibility and pathogenicity of Verticillium dahliae from spearmint and peppermint. Plant Dis. 85:297-302.
17. Elena, K. 1999. Genetic relationships among Verticillium dahliae isolates from cotton in Greece based on vegetative compatibility. Eur. J. Plant Pathol. 105:609-616.

18. Gómez, K. A., and Gómez, A. A. 1984. Statistical Procedures for Agricultural Research, 2nd ed. John Wiley and Sons, New York.

19. Goud, J. C., and Termorshuizen, A. J. 2002. Pathogenicity and virulence of the two Dutch VCGs of Verticillium dahliae to woody ornamentals. Eur. J. Plant Pathol. 108:771-782.

20. Jiménez-Díaz, R. M., Mercado-Blanco, J., Olivares-García, C., Collado-Romero, M., Bejarano-Alcázar, J., Rodríguez-Jurado, D., Giménez-Jaime, A., García-Jiménez, J., and Armengol, J. 2006. Genetic and virulence diversity in Verticillium dahliae populations infecting artichoke in eastern-central Spain. Phytopathology 96:288-298.

21. Joaquim, T. R., and Rowe, R. C. 1990. Reassessment of vegetative compatibility relationships among strains of Verticillium dahliae using nitrate-nonutilizing mutants. Phytopathology 80:1160-1166.

22. Joaquim, T. R., and Rowe, R. C. 1991. Vegetative compatibility and virulence strains of Verticillium dahliae from soil and potato plant. Phytopathology 81:552-558.

23. Katan, T. 2000. Vegetative compatibility in populations of Verticillium-an overview. Pages 69-86 in: Advances in Verticillium: Research and Disease Management. Proc. 7th Int. Verticillium Symp. E. C. Tjamos, R. C. Rowe, J. B. Heale, and D. R. Fravel, eds. The American Phytopathological Society, St. Paul, MN.

24. Koike, S. T., Subbarao, K. V., Davis, R. M., Gordon, T. R., and Hubbard, J. C. 1994. Verticillium wilt of cauliflower in California. Plant Dis. 78:1116-1121.

25. Korolev, N., and Katan, T. 1997. Improved medium for selecting nitrate nonutilizing (nit) mutants of Verticillium dahliae. Phytopathology 87:1067-1070.

26. Korolev, N., Katan, J., and Katan, T. 2000. Vegetative compatibility groups of Verticillium dahliae in Israel: their distribution and association with pathogenicity. Phytopathology 90:529-566.

27. Korolev, N., Pérez-Artés, E., BejaranoAlcázar, J., Rodríguez-Jurado, D., Katan, J., Katan, T., and Jiménez-Díaz, R. M. 2001. Comparative study of genetic diversity and pathogenicity among populations of Verticillium dahliae from cotton in Spain and Israel. Eur. J. Plant Pathol. 107:443-456.

28. Korolev, N., Pérez-Artés, E., Mercado-Blanco, J., Bejarano-Alcázar, J., Rodríguez-Jurado, D., Jiménez-Díaz, R. M., Katan, T., and Katan, J. 2008. Vegetative compatibility of cottondefoliating Verticillium dahliae in Israel and its pathogenicity to various crop plants. Eur. J. Plant Pathol. 122:603-617.

29. Leslie, J. F. 1993. Fungal vegetative compatibility. Annu. Rev. Phytopathol. 31:127-150.

30. Mercado-Blanco, J., Rodríguez-Jurado, D., Parrilla-Araujo, S., and Jiménez-Díaz, R. M. 2003. Simultaneous detection of the defoliating and nondefoliating Verticillium dahliae pathotypes in infected olive plants by duplex, nested polymerase chain reaction. Plant Dis. 87:1487-1494.

31. Mercado-Blanco, J., Rodríguez-Jurado, D., Pérez-Artés, E., and Jiménez-Díaz, R. M. 2001. Detection of the nondefoliating pathotype of Verticillium dahliae in infected olive plants by nested PCR. Plant Pathol. 50:1-12.

32. Mercado-Blanco, J., Rodríguez-Jurado, D., Pérez-Artés, E., and Jiménez-Díaz, R. M.
2002. Detection of the defoliating pathotype of Verticillium dahliae in infected olive plants by nested PCR. Eur. J. Plant Pathol. 108:1-13.

33. Nigro, F., Gallone, P., Romanazzi, G., Schena, L., Ippolito, A., and Salerno, M. G. 2005. Incidence of Verticillium wilt on olive in Apulia and genetic diversity of Verticillium dahliae isolates from infected trees. J. Plant Pathol. 87:13-23.

34. Peever, T. L., Canihos, Y., Olsen, L., Ibañez, A., Liu, Y. C., and Timmer, L. W. 1999. Population genetic structure and host specificity of Alternaria spp. causing brown spot of Minneola tangelo and Rough lemon in Florida. Phytopathology 89:851-860.

35. Pegg, G. F., and Brady, B. L. 2002. Verticillium Wilts. CAB International, Wallingford, UK.

36. Qin, Q. M., Vallad, G. E., Wu, B. M., and Subbarao, K. V. 2006. Phylogenetic analyses of phytopathogenic isolates of Verticillium spp. Phytopathology 96:582-592

37. Rauyaree, P., Ospina-Giraldo, M. D., Kang, S. Bath, R. G., Subbarao, K. V., Grant, S. J., and Dobinson, K. F. 2005. Mutations in VMK1, a mitogen-activated protein kinase gene, affect microsclerotia formation and pathogenicity in Verticillium dahliae. Curr. Genet. 48:109-116.

38. Resende, M. L. V., Flood, J., and Cooper, R. M. 1994. Host Specialization of Verticillium dahliae, with emphasis on isolates from cocoa (Theobroma cacao). Plant Pathol. 43:104-111.

39. Rowe, R. C. 1995. Recent progress in understanding relationships between Verticillium species and subspecific groups. Phytoparasitica 23:31-38.

40. Ryder, E. J., De Vos, N. E., and Bari, M. A 1983. The Globe artichoke (Cynara scolymus L.). HortScience 18:646-653.

41. Schnathorst, W. C., and Mathre, D. E. 1966. Host range and differentiation of a severe form of Verticillium albo-atrum in cotton. Phytopathology 56:1155-1161.

42. Shah, D. A., and Madden, L. V. 2004. Nonparametric analysis of ordinal data in designed factorial experiments. Phytopathology 94:3343.

43. Strausbaugh, C. A., Schroth, N. M., Weinhold, A. R., and Hancock, J. G. 1992. Assessment of vegetative compatibility of Verticillium dahliae tester strains and isolates from California potatoes. Phytopathology 82:61-68.

44. Subbarao, K. V., Chassot, A., Gordon, T. R. Hubbard, J. C., Bonello, P., Mullin, R., Okamoto, D., Davis, R. M., and Koike, S. T. 1995 Genetic-relationships and cross pathogenicities of Verticillium dahliae isolates from cauliflower and other crops. Phytopathology 85:1105-1112.

45. Tjamos, E. C. 1981. Virulence of Verticillium dahliae and Verticillium albo-atrum isolates in tomato seedlings in relation to their host of origin and the applied cropping system. Phytopathology 71:98-100

46. Tsror, L., Hazanovsky, M., Mordechi-Lebiush, S., and Sivan, S. 2001. Aggressiveness of Ver ticillium dahliae isolates from different vegetative compatibility groups to potato and tomato. Plant Pathol. 50:477-482.

47. Zeise, K., and von Tiedemann, A. 2002. Application of RAPD-PCR for virulence type analysis within Verticillium dahliae and V. longisporum. J. Phytopathol. 150:557-563.

48. Zeise, K., and von Tiedemann, A. 2002. Host specialization among vegetative compatibility groups of Verticillium dahliae in relation to Verticillium longisporum. J. Phytopathol. 150:112-119. 